\title{
FRANCISCO CABALLERO SARMIENTO, UN EMPRESARIO AL SERVICIO DE LA CONTRARREVOLUCION EN VENEZUELA, 1806-1819
}

\author{
POR \\ MANUEL HERNANDEZ GONZALEZ \\ Universidad de La Laguna
}

\section{El RÉgimen dE COMERCIO PRIVILEgIado DE LOS CRAIG EN VENEZUELA}

Francisco Caballero Sarmiento, comerciante de origen portugués, afiancado desde muy temprana edad en Filadelfia, se puede considerar el prototipo de una generación de empresarios norteamericanos que supieron aprovechar las oportunidades que les ofrecía las contradicciones y deficiencias del régimen comercial español. Desde 1787 se instaló en uno de sus eslabones más débiles, las islas Canarias, centro de un relativamente importante comercio con los Estados Unidos y desde donde planeó su introducción en el rico y ventajoso mercado de la América Española (1). A lo largo de este trabajo trataremos de abordar un aspecto de su trayectoria, esto es, el papel jugado por Caballero Sarmiento en la trama de la guerra de independencia venezolana.

Francisco Caballero Sarmiento, casado con Catalina Craig, hija del comerciante de Filadelfia James Craig, es un fehaciente exponente de una generación de mercaderes norteamericanos ávidos por penetrar en el mercado de la América Española y, que

Sigl.AS UTILIZADAS:

AGI: Archivo General de Indias (Sevilla).

AHN: Archivo Histórico Nacional (Madrid).

AHPT: Archivo Histórico Provincial de Tenerife.

NA: National Archives (Washington).

(1) Manuel Hernández González, Manuel de Paz Sánchez, "Francisco Caballero Sarmiento y Canarias, Noticias sobre un comerciante ilustrado", Anuario de Estudios Atlánticos, $\mathrm{n}^{0}$ 31. Madrid-Las Palmas, 1985. Agustín Guimera Ravina, Burguesia extranjera de comercio atlántico. La empresa comercial irlandesa en Canarias (1703-1771). Tenerife, 1985. 
fueron conscientes de las posibilidades que les brindaba la debilidad interna de las estructuras socio-políticas y económicas de la Monarquía Española, y que supieron con habilidad aprovecharlas a través de su estudiada y meditada introducción dentro de las redes de poder de la burocracia española.

Aunque nació en Lisboa y uno de sus padres era gallego, a Caballero Sarmiento por su formación se le puede considerar, en lo que respecta al conocimiento de las finanzas y del comercio, una persona forjada en Filadelfia. Su espíritu agresivo en materia comercial y su estrategia familiar en el mundo mercantil se puede caracterizar como enteramente norteamericana, incluso en el efectivo partido que supo sacar de su origen español. A lo largo de su vida utilizó con igual efectividad la invocación de sus nacionalidades española y norteamericana. Durante numerosos años Caballero Sarmiento participó activamente en compañías en las que participaban John Craig y Robert Oliver - hermano y cuñado respectivamente de su mujer- en las que se puede apreciar la estrategia planificada de alianzas familiares que envolvía las acusaciones de la burguesía norteamericana de fines del siglo XVIII y comienzos del siglo XIX. Si a ello unimos que la hija de John Craig contrajo matrimonio con Nicholas Biddle, director del segundo Banco de los Estados Unidos y destacado político e intelectual norteamericano; que el hijo de ambos, Edward, se casó con la nieta de Sarmiento, que ya con anterioridad había contraído matrimonio con el hijo de John Craig que llevaba su mismo nombre, y por último, que la hija de Sarmiento se casó con Eduardo Barry, natural de Tenerife, heredero de la fortuna de su tío del mismo nombre, e introductor en régimen cuasimonopolítico de los esclavos negros en Venezuela, el panorama de una estricta política de endogamia explica la estrategia matrimonial de la familia Craig, forjada por James Craig desde los años en los que emigró a Estados Unidos desde Escocia (2).

Durante sus años de estancia en las islas Canarias, Francisco Caballero Sarmiento había tratado que sus actividades comerciales adoptaran prácticas monopolistas. Su campo de acción se orientó hacia la política de concesión de gracias y privilegios. Uno de los puntos cardinales de la actuación de Caballero Sar-

(2) Nicholas Wainwright, "Andalusia, Countryseat of the Craig Family and of Nicholas Biddle and his descendents", The Pennsylvania Magazine of History and Biography, $\mathrm{n}^{Q}$ 101. Fladelfia, 1977; Stuart BRUCHERS, Robert Oliver, merchant of Baltimore, 1783-1819, Baltimore, 1956; HERNÁNDEZ y DE PAZ (1]. Sobre Nicolas Briddle véase, Thomas PAYNE, Nicholas Biddle, nationalista and Public Banker, 1786-1844. Chicago, 1959. 
miento en Canarias, fue entablar estrechas relaciones con la burocracia española. Allí conoció al cuñado de Godoy, el Marqués de Branciforte, futuro Virrey de México, que desempeñaba por aquel entonces el cargo de Comandante General de las islas, y a través de su activo tráfico entre Canarias y los Estados Unidos y de las relaciones de su cuñado y socio, John Craig, entabló una estrecha amistad con el representante de España en ese país, el Marqués de Casa-Irujo, cuyas empresas comerciales con la burguesía norteamericana son ampliamente conocidas (3). Desde entonces, excepto en el conflictivo consulado de Valentín de Foronda, la unidad de intereses entre los embajadores españoles y Caballero Sarmiento fue prácticamente total. El peso de Sarmiento en diferentes camarillas de la Corte fue tal que incluso logró que la Inquisición Central paralizase un proceso incoado en su contra, e incluso llegó a presumir de utilizar la carroza de Godoy (4). La directa imbricación de sus operaciones mercantiles con el Estado Español hacía posible que compatibilizase su cargo como alto funcionario de la Hacienda y como comisionado para la liquidación y cobranza de las deudas del Real Erario en las expediciones neutrales de las guerras que vivió España a partir de 1797, con su papel de comerciante implicada directamente en los mismos, lo que le llevó en los últimos años de su vida, cuando la camarilla que le apoyaba perdió poder en la Corte, a una auténtica persecución, que según su familia finalizó con su asesinato (5).

La estrecha alianza de intereses entre sectores de la burguesía comercial norteamericana, entre los que destaca poderosamente el linaje Craig, que hasta la muerte de John Craig en 1807 actuará en muchas empresas como un todo, y la burocracia godoista, tuvo su punto de arranque más trascendental en 1797 cuando España autorizó el comercio de sus coloniales con los buques de naciones amigas neutrales en el marco de una guerra contra Gran Bretaña.

En 1800 John Craig y Robert Oliver ya se habían introducido activamente en el mercado venezolano. Un viaje a La Guaira les había proporcionado un beneficio de 4.775 dólares. En el contrato estaba envuelto el Gobierno Español y el propio Intendente lo

(3) Jacques Barbier y Alan Kuethe, A. eds. The North American role in the Spanish Imperial economy, 1760-1819. Manchester, 1984.

(4) HeRnándeZ y de PAZ [1], pág. 466.

(5) AHN. Estado, Leg. 5.551. W AinWRight [2], pág. 22. 
había firmado (6). Numerosas compañías intentaron controlar este floreciente mercado mediante regímenes de privilegio y toda una tejida red de influencias y de conexiones familiares se desarrolló para beneficiarse de esta situación.

Desde esta perspectiva puede apreciarse la unidad de intereses entre la familias Craig y Barry. Eduardo Barry había obtenido en 1784 una contrata mediante la cual podía introducir 4.000 esclavos negros en Trinidad. Barry no sólo se convirtió a partir de esas fechas en un floreciente negociante con la trata sino que se estableció en Trinidad, donde se convirtió en un acaudalado hacendado con plantaciones de caña de azúcar. Tras su fallecimiento en 1805, su hermano Diego - un acaudalado comerciante del Puerto de la Cruz en Tenerife especializado en el comercio con Estados Unidos- dio plenos poderes a Francisco Caballero Sarmiento, su consuegro, para que lleve a efecto

«la contrata para abastecer de negros la provincia de Caracas hecha por Don Eduardo Barry en 16 de diciembre de 1795 y que habiendo muerto la llevase en todas sus partes el otorgante su hermano como consta del Real Despacho con fecha en Aranjuez a 4 de marzo de 1804, cometiendo para su inteligencia y cumplimiento al Señor Intendente de Caracas» (7).

A partir de entonces y de forma progresiva las compañías norteamericanas, y en especial la casa Craig, aprovechándose de la situación bélica en Europa se fueron apoderando del mercado venezolano a través de la compra de privilegios comerciales. A fines de noviembre de 1805 llegó a La Guaira el primer buque de Craig. Sucesivos convoyes de Craig y de Luke y Tiernan de Baltimore controlaron el mercado ante la ausencia de mercantes españoles y de otros países amigos o neutrales. La quiebra fue una norma general en numerosas compañías comerciales caraqueñas. Las quejas y el disgusto comenzaron a hacerse eco entre las élites sociales y estos monopolios se convirtieron en una espoleta (8). En la Junta General de Comercio de 27 de marzo de 1806 acusaron a Caballero Sarmiento de estar ejerciendo un verdadero monopolio. Se denunció el hecho de que un extranjero

(6) BRUCHEY [2], págs. 209-211.

(7) AHPT. Leg. 3.856. Sobre Eduardo Barry, véase Miguel Acosta Saicenes, La vida de los esclavos negros en Venezuela. Caracas, 1967, págs. 44-62. y Jesse A. NoEl, Trinidad, Provincia de Venezuela, Caracas, 1972.

(8) Manuel Lucena, Vísperas de la independencia americana: Caracas. Madrid, 1986, pág. 296. 
por este privilegio «había establecido su dominación sobre toda la vida económica de la provincia. Esto era contrario al sistema de libertad de igualdad comercial tan necesario para el bienestar y el progreso de los propios súbditos del Rey» (9).

La Compañía formada por la familia Craig no se limitó a la importación de productos procedentes de Estados Unidos, sino que mantuvo un activo comercio con las colonias extranjeras del Caribe mediante barcos franceses o daneses que trasladaban a La Guaira tejidos franceses, plomo, bacalao, velas, etc., y exportaban café, añil, cueros, azúcar, cacao... El Intendente, en un informe de 28 de julio de 1806, hacía constar las dificultades de "quitar todas las trabas a unas negociaciones que por documentos reservadamente presentados constaba ser pertenecientes a la casa de Amortización». La exigencia de retener las fianzas hasta que se abonasen en España por parte de los fiadores, todos ellos conocidos miembros de la burguesía comercial caraqueña como Francisco González de Linares, Salvador Eduardo y Joaquín García Jove, causaba «indecibles perjuicios en la Real Caja de Amortización que en ningún tiempo necesitaba más de qualquiera caudales que en la época presente». Sarmiento reconoce laș dificultades de este privilegio, pues los enemigos declararon por buena presa cualquier embarcación de su pertenencia, por lo cual solicitaban que se tomasen «medidas y precauciones supletorias como poner las expediciones en otros nombres, silenciar el privilegio y omitir aquellas formalidades que puedan auxiliar los proyectos del enemigo" (10).

Las estrechas conexiones entre los intereses de la Real Hacienda y de la Compañía Craig disgustaban tanto a la burguesía caraqueña como a Inglaterra, y era sin duda un factor de perturbación de negativas consecuencias para la Monarquía española en el futuro bien próximo con la cada vez más contumaz disociación de objetivos en el comercio venezolano y el Estado Español.

El privilegio de la Casa Craig, por las presiones del Consulado caraqueño aparentemente se suprimió, pero en realidad él sustituyó otra real orden todavía más escandalosa y que contribuía explicar todavía más esa identidad de intereses entre la burocracia godoista y los Craig. En 1803, el Marqués de Branciforte, viejo conocido de Sarmiento, obtuvo el privilegio de introducir

(9) Humberto Tandron, H. El Real Consulado de Caracas y el comercio exterior de Venezuela. Caracas, 1976, págs. 183-184.

(10) AGI. Audiencia de Caracas. Leg. 899. 
100.000 barriles de harina en Venezuela y Cuba. La Caja de Consolidación compró el privilegio y lo cedió a la Casa Craig. La orden se publicó en Caracas el 11 de diciembre de 1806. La oposición del Consulado caraqueño fue inmediata. Entre las razones esgrimidas de cómo un extranjero como Sarmiento «estaba adquiriendo un control extremo sobre la vida económica de Venezuela cuando la provincia estaba en peligro aún de ser atacada y después de que los venezolanos habían probado ser tan leales súbditos del Rey" (11).

En esta severa crítica realizada cuando el país se encontraba bajo la frustrada invasión de Miranda, que comentaremos más adelante, participaron el Capitán General y el Intendente por el uso de la expresión monopolio en un negocio en el que estaba interesado directamente el Rey, por lo que se consideraba una falta de respeto y a lo que el Consulado replica que la misión del Rey era la de proteger la prosperidad del Estado. El creer que los intereses de la Monarquía estaban en contra del bienestar de sus súbditos era un síntoma de graves perturbaciones. Y aún así el Consulado no recibió respuesta alguna de sus quejas; era un terreno abonado para la disidencia en cuanto las circunstancias fueran favorables (12).

Lucena Salmoral estima que los beneficios de la Casa Craig durante los veinte meses de duración del monopolio (desde febrero de 1807 hasta el 28 de octubre de 1808) fueron de 200.000 pesos, más los 300.000 que pagó a Branciforte, y eso sin tener en cuenta los negocios en Cuba que merecerían renglón aparte. Pero además, la Casa Craig no pagó los derechos estipulados por la Caja de Consolidación, por lo que ésta lo reclamó.

Sarmiento se embarcó para Filadelfia y cuando llegó se encontró moribundo a su cuñado John Craig (13). En efecto, el 29 de mayo de 1807 falleció tras sellar su última voluntad testamentaria. Años más tarde, en 1829, Catalina Craig, ya viuda de Sarmiento, diría que John Craig en su testamento había acordado remitir a Europa 2 cargamentos de cacao y otros frutos destinados sus productos a la Caja de Consolidación, pero uno de ellos retornó por averías y el otro fue apresado en la ría de Burdeos. Este último pudo ser reclamado a los aseguradores en los EE.UU., pero no constaba ese reembolso. Tal era la "complejidad finan-

(11) Vid. [9], págs. 186-188.

(12) Ibidem, págs. 188-189.

(13) Vid [8], págs. 304-305. 
ciera» de la Compañia Craig. Mas la muerte de John Craig marcó la ruptura definitiva de esa empresa familiar.

A partir de esa fecha, como tendremos ocasión de ver más adelante, Caballero Sarmiento actuó ya por cuenta propia. La hija de John Craig, Jane, contrajo matrimonio con Nicholas Biddle y el apoyo a las actuaciones de Sarmiento no fue ya incondicional. La compleja situación internacional de 1808 y de los años posteriores hizo recapacitar a la burguesía norteamericana de los riesgos de tomar abierto partido por una opción en el comercio con la América Española, actividad a la cual no fueron ajenos Nicholas Biddle y Robert Oliver. La ruptura con Sarmiento, que optó decididamente por cifrar todas sus esperanzas comerciales en la continuidad de dominio español en el cono sur americano, llegó hasta sus últimas consecuencias en su mismo matrimonio con la separación de su mujer y con el partido decidido de su yerno Eduardo Barry por la causa independentista, llegando a ser representante en Filadelia de la Gran Colombia (14).

\section{La inVASIÓN DE MiRANDA DE 1806 Y LA CONJURACión DE Matos}

El primer intento de Francisco de Miranda de invadir Venezuela resultó ser un fracaso. Aconteció en abril de 1806 y aparentemente no se tradujo en un apoyo masivo por parte de los grupos sociales dominantes a las ideas separatistas, pero sí tuvo importantes consecuencias en el agravamiento de la situación. Aunque fue decretado el libre comercio con las naciones neutrales el 25 de junio de 1806 para aplicar los graves problemas financieros ocasionados por la invasión, la ya citada gracia concedida a Branciforte devolvió la situación a su anterior estado y los privilegios concedidos a Sarmieno a raíz de su participación en el rechazo de la misma la agravaron aún más (15).

La invasión de Miranda puso sobre el tapete quien era el auténtico amo de la situación en Venezuela, y mostró las debilidades de los poderes establecidos para hacer frente a la situación. El ministro plenipotenciario de España en los Estados Unidos, el Marqués de Casa Irujo, que operaba en estrecha conexión con Caballero Sarmiento, proporcionó al Capitán General de Venezuela, Guevara Vasconcelos, una exacta noticia de sus movi-

(14) Wainwright [2], págs. 17-22. y NA Sign. M51, 2.

(15) Vid. [9], pág. 182. 
mientos. Para hacer frente a tales amenazas, Guevara, como él mismo señalaba personalmente:

«necesitando despachar un buque a la parte de la isla de Santo Domingo que tiraniza el negro Desalines, donde debía completarse el armamento para averiguar su fuerza, designios, y apoyos con que contaba en este país y otras noticias, constándome la generosidad y ardiente amor del capitán de milicias de Canarias Don Francisco Caballero Sarmiento, le llamé y proponiéndole si podría aprontarme un barco para que saliese inmediatamente a dicha isla sin vacilar un instante me allanó en el momento una goleta muy velera que había en La Guaira sin descargar, compró a este fin sin ninguna necesidad su cargamento que por ser de pertrechos navales no era fácil darle salida en la estación actual, lo descargó, enlastró y alistó con tal esmero que las 24 horas dio vela. En la oscuridad que ofrecía la elección de sujeto de confianza y reserva que pasase en este buque a practicar las citadas observaciones me facilitó también bajo una cuantiosa y voluntaria responsabilidad a un sujeto que llevó este encargo a mi satisfacción y cuya actividad produjo muy notorias ventajas a la tranquilidad pública».

Asimismo exponía que los gastos de toda esta expedición, que cifraba en 6.000 pesos corrieron a cargo de Sarmiento, que "estimulado de la indigencia del Real Erario, de su celo y distinguido amor a Su Majestad le hizo generosa donación de ellos».

A consecuencia de ello, por Real Despacho dado en San Lorenzo a 11 de octubre de 1807, se le concedió el grado de Coronel de Milicias (16). Pero a la vez de ello su solicitud iba "dirigida a obtener privilegios para introducción de efectos».

El espía que Sarmiento puso al mando de ese buque había trabajado a su servicio y estaba alojado en su misma casa. Se llamaba José Cobachich, era natural de Venecia y cumplió a la perfección la misión informativa que se le había encomendado. Por sus servicios se le dio el título de Comisario de Guerra de los Reales Ejércitos (17). Había aprendido muy bien la lección de su jefe y solicitó «algún privilegio de introducción libre de géneros en la misma Provincia de Venezuela donde ha contraído tan relevantes méritos y libre extracción de una determinada cantidad de granos». Hizo alusión a que había gastado una imaginaria

(16) AHN. Sección Estado, Leg. 5.551.

(17) Hector García Chuecos, Relatos y comentarios sobre temas de Historia Venezolana. Caracas, 1967, págs. 244-247. 
cantidad de dinero en la expedición, que cifró en 29.350 pesos, por lo que se enfrentó con Sarmiento, poniendo por testigo al Marqués de Casa-Irujo. Más como este último exponía en una carta dirigida al veneciano «bien dice el refrán de que la codicia rompe el saco. Usted a fuerza de querer ganar dinero no sólo quiere deshonrarse, sino que pretende deshonrarme» (18).

Estos acontecimientos ponen a las claras la situación por la que atravesaba Venezuela. Sarmiento practicaba la misma política que ya había experimentado con éxito desde su estancia en las islas Canarias, acaparar gracias y concesiones regias a través de servicios personales a la Corona. Pero la exhibición de su poderío ante la manifiesta incapacidad del Capitán General dejaba a las claras qué grado de dependencia tenía el poder político de su casa de comercio.

A este respecto Miranda comentaba el 3 de julio de 1809 que

«un tal Sarmiento (Portugués) al Indio Obediente de Curacao digno agente de asesinos y envenenadores y otros de esta laya habían dado muchas recompensas en dinero y honores por los servicios de espionaje que habían practicado cuando yo estuve por la costa, y ellos temblaban de miedo; que el genovés Bachichi, que estuvo en Jaquemel... y un... habían también recibido estas infames recompensas» (19).

La frustrada invasión de Miranda demostró que las clases sociales dominantes no habían optado todavía por la causa de la independencia, por el recelo que tenían hacia Miranda y su política excesivamente liberal y antiesclavista, y porque pensaban que el poder español pese a su debilidad podía seguir garantizando una cierta estabilidad social en una sociedad esclavista como la venezolana, asustada ante el impacto de la revolución haitiana; de ahí que no sea casual el apoyo masivo que en donativo dio la élite caraqueña para impedir la invasión. En las listas, publicadas en la Gaceta de Caracas durante los meses de abril y mayo de 1809, aparece Sarmiento con un donativo de 500 pesos. Significativamente la mayor donación correspondía a Fernando Key y Muñoz, y la Casa de Muñoz y Orea con 1.000 pesos, un canario que después desempeñó el cargo de Ministro de Hacienda de la Primera República de Venezuela.

Las gracias exclusivas concedidas a Sarmiento reactivaron un

(18) AHN. Estado. Legs. 5.544 y 5.545. 383.

(19) Archivo del General Miranda. La Habana, 1950, tomo XXII, págs. 382 - 
estado de áspera crítica en el seno de las clases dominantes criollas angustiadas por la situación cada vez más negativa de su comercio. El 26 de agosto de 1808, el Síndico Personero del Real Consulado de Caracas envió un informe a la recién creada Junta Central de Sevilla, fehaciente testimonio de la crispación ambiental, en él exponía los perjuicios que al país han ocasionado las gracias concedidas «con motivo de algunos servicios en las ocurrencias de la expedición del Traidor Miranda, "que» es un modo de premiar servicios figurados o justos capaz de los mayores fraudes e indecoroso a la consideración y respecto que es debida a los hombres, son odiosas hasta el último grado y un antídoto para destruir a la Real Hacienda, comercio y agricultura». Además señalaba que se les dispensaba a los agraciados la mitad de los derechos establecidos para el comercio colonial, lo que les proporcionaba unas enormes ganancias y eliminaba toda competencia. En su informe de 26 de septiembre de ese año el Síndico acusaba al Capitán General de valerse «de simulados informes que hizo al ministerio con motivo de las fantásticas ocurrencias de la expedición de Miranda" y los atribuye a "un espíritu de egoísmo, el mismo que reinaba en la Corte al abrigo y protección de aquel tirano que tenía oprimidos hasta a los mismos soberanos".

Los géneros importados eran considerados como si fuesen españoles, conducidos desde la Península y por tal motivo señalaba que la Real Hacienda había perdido más de 200.000 pesos: «El comercio no puede subsistir así, los privilegios particulares le preparan la más completa disolución». Para éste, obstruido el comercio con Europa por el bloqueo napoleónico, el contrabando era la única solución para subsistir, asimismo, exponía la situación que había conducido a Venezuela al régimen de privilegios:

«El Gobierno, conducido siempre por unas corporaciones oscuras y misteriosas consigue tenernos con un velo que aleje de nuestra comprensión las determinaciones que convendría tuviésemos noticia; de qué medios y artificios desusados se habrá valido para mover esta desorganizada máquina de gracias en los términos más disonantes del honor, de la razón, de la justicia y del respecto que es debido a los hombres. Pasa de un millón de pesos el valor de las gracias del comercio concedidas cuasi todo el presente año, cerca de la mitad del giro total que hacen estas provincias" (20).

(20) AGI. Audiencia de Caracas. Leg. 804. Vid [8], págs. 297-305. 
Vivo testimonio de ese ambiente de opinión cada vez más crítico hacia el Gobierno fue la llamada Conjuración de Matos en julio de 1808 en la que se apostaba decididamente por la independencia y en la que el monopolio de Sarmiento se puede apreciar como uno de los estimuladores de ese estado de opinión, llegándose a decir por el Consulado que Sarmiento

«...éste constituido en árbitro del giro universal del país, teniéndolo, digámoslo así, en una mano la llave que abre y cierra las puertas según más convenga a sus particulares intereses, y en la otra mano la vara milagrosa que dirige y gobierna el giro del país, poniendo trabas a todo lo que le comprende; circunstancias todas que si serían notables y odiosas en Español a quién la casualidad y, unas extraordinarias circunstancias hubieran colocado en esta especie de Soberanía Mercantil, ha de ser precisamente más reparable en un extranjero sin mérito ni utilidad conocida que naturalmente ha de abusar de este singular predominio, sin las atenciones que un compatriota que tendría respetos que mirar sobre los de su peculiar interés" (21).

El propio Matos expresó en la conjura con claridad la situación tal y como era analizada por los grupos sociales dominantes criollos:

«Descendió a tratar sobre una R.O. que recibió el Señor Capitán General difunto en que se advertía no esperarse auxilio alguno de la Metrópoli, dejándose a su arbitrio el declarar el comercio libre con las potencias neutrales, la que el expresado Señor ni el Señor Intendente quisieron poner en práctica, lo que ha originado la ruina de la provincia, especialmente la de sus hacendados. También trató de la gracia exclusiva a Sarmiento del comercio; que esto era verdaderamente un estanco. Que al vecindario se le obligaba a comer pan por el precio y con la calidad que él quería gracia seguramente del tirano y déspota Godoy y que esperaba justo castigo a tan execrable delito de infamia y que en el día apenas tenía para comer, sin embargo de que se hallaba con más de setecientos quintales de café, a los que no se ha podido dar salida» (22).

(21) Mercedes Alvarez, Comercio y comerciantes y sus proyecciones en la indenpendencia de Venezuela. Caracas, 1964, pág. 118.

(22) Boletín de la Academia Nacional de la Historia, no 52. Caracas, 1930, págs. 615-616. Véase también, Vicente LecunA, "La Conjuración de Matos". Boletín de la Academia Nacional de Historia, $n^{0}$ 56. Caracas, 1931, pág. 381-440, y Mercedes Alvarez, [21], págs. 123-124. 
La exasperación de los hacendados y los comerciantes criollos era notable. Las palabras de Matos son elocuentes por sí solas:

«...ha llegado el tiempo en que los americanos gocemos de nuestra libertad; en la presente ocasión es necesario que salgamos de todos los españoles y quedemos sólo los criollos y los isleños porque éstos son buenos; deben abolirse los estancos y demás pechos y Ud. a quien puede influirle esta máxima no se excuse, pues en ellos obrará caritativamente... que se no estaba viendo que los jueces españoles no trataban otra cosa que de robarnos; que el Señor Intendente era un pícaro contrabandista, por cuyo motivo había confundido la Real Cédula en que S.M. concedió cierta gracia con respecto a los algodones y cafeses; que é́l tenía porción de quintales y no los había podido vender».

Las intrigas del pérfido Godoy y de sus representantes en Venezuela lo que habían hecho

«...era tiranizar a los patricios de aquí con la gracia exclusiva a Sarmiento de harinas, el que se aprovechaba vendiéndolas al público a un precio muy alto y muy malas; que el entorpecimiento del comercio dependía de las intrigas y cohechos que recibían todos aquellos que habían tenido el favor de Godoy, y que así resultaba que todo el pueblo estaba oprimido y afligido" (23).

El 15 de noviembre de 1808 la Junta Central de Sevilla había ordenado la supresión del monopolio de las harinas, suspensión que ya se había decretado en Venezuela el 27 de octubre de 1808. La abierta oposición de los mantuanos aconsejaba esa decisión. El 24 de noviembre la llamada conjuración de 1808 exigía la creación de una Junta Gubernativa. La invasión de la Península Ibérica por los franceses suponía el fin de un orden de cosas en el que el Estado Español legitimaba y garantizaba el sistema social en la colonia. Los acontecimientos se acelerarían y el camino hacia la proclamación de la independencia el 19 de octubre de 1810 estaba abierto (24).

Como señala J. A. Alvarez Rixo, finalizado el monopolio, con el que "ganó millones con el repetido permiso de ser el único introductor de harinas allí, hasta que hecha la paz con Inglaterra

(23) Vid. [21], págs. 124-126.

(24) Vid. [21], págs. 127-130. Vid [8], cit. pág. 306. 
y las consecuentes alternaciones de gobierno de 1808 y 1809 regresó a Filadelfia» (25).

\section{Sarmiento y la Primera RePÚblica Venezolana}

No queremos en este apartado, porque saldría fuera de los reducidos límites de un artículo, trazar el complejo panorama de Sarmiento desde el momento en que abandona Venezuela, se establece en Filadelfia, y muere en Madrid. Nos limitaremos a analizar sus actividades relacionadas con las guerras de la Independencia de la América Española.

Las estrechas conexiones existentes entre los embajadores españoles y los Craig, con la excepción de los años en que Valentín de Foronda fue cónsul español en los Estados Unidos, se confirman con Luis de Onís. Aunque no fue reconocido por Norteamérica hasta 1815, Onís desempeñó ese cargo desde 1809. La complejidad de una España invadida por los franceses y el no reconocimiento de la legitimidad de su mandato por la.Junta Central de Sevilla complicó la situación. Desprovisto de medios económicos para contrarrestar la influencia de los movimientos separatistas de la América Española, supeditará sus actividades a su estrecha dependencia de Sarmiento. Sus empresas comerciales y políticas asumirán esa doble caracterización, nada rara si tenemos en cuenta los notables beneficios que en el pasado había proporcionado al Marqués de Casa-Irujo.

Sarmiento se convierte, pues, a la vez en un omnipresente agente del gobierno español, en un empleado de la Caja de Consolidación y en un empresario que actúa consecutivamente como comerciante; prestamista y propietario de unos bienes que supuestamente son estatales. Esta aparente confusión que formaba parte de sus actividades mercantiles le llevó a identificar su causa y sus negocios con una empresa particular que estaba condicionada estrechamente con la causa española. Ese apoyo incondicional que les llevó a la separación y a la disputa interna en su propia familia le ocasionó también la ruina de su empresa al fracasar la causa realista en la América Española.

Como el mismo refiere, «no habiendo fondos para desempeñar

(25) José Agustín Alvarez. Rixo, Biografia de Francisco Caballero Sarmiento. Manuscrito. Archivo de los Herederos de Alvarez Rixo. Puerto de la Cruz. Tenerife. Véase HERnández y de PAZ, [1], pág. 434. 
varias comisiones del Real Servicio que se confiaron al señor don Luis de Onís ministro plenipotenciario y enviado extraordinario de la Corte de España en los Estados Unidos, adelantó crecidas sumas de su caudal propio para compra de goletas y armas sin interés alguno, por cuyo motivo se ejecutó aquella comisión». De la misma refiere que resultó un balance a su favor de 49.781 pesos y 52 centavos y medio que aún no se le habían satisfecho en 1816 (26).

A partir de entonces las empresas comerciales y bélicas de Sarmiento y Onís se sucedieron, y tras la compra del bergantín Regencia para el virreinato de México cuyo importe no le fue abonado por su gobierno, compraron de nuevo otro buque para «llevar noticias de importancia a Buenos Aires para que pasase en él un ménsajero despachado por el Plenipotenciario, quien le fletó dicho buque y que no habiéndole pagado el flete en Buenos Aires como estaba estipulado, se le causó un perjuicio, volviéndose el buque en lastre después de una detención de más de 3 meses por falta de aquellos fondos para cargar» (27).

La supuesta misión a Buenos Aires tropezó con un inconveniente tras llegar a esa ciudad, como refiere una carta fechada en la actual capital de Argentina el 8 de junio de 1811, reproducida en la Aurora de Filadelfia, la cual reproducimos en parte:

«La Junta de aquí embarcó para España a las 10 de la noche al Señor Virrey y a 4 de los consejeros... Un bergantín perteneciente a un tal Sarmiento que me parece reside en esa ha llegado aquí con un hijo de uno nombrado Fatio, como encargado de despachos de algún caballero español que se dice ministro español cerca de los Estados Unidos. No sabíamos aquí que había embajador español en la América Septentrional, y a la verdad ninguno de los americanos así lo creían, aunque sí lo creían los españoles... Este reputado ministro y Sarmiento han sido aquí públicamente declarados socios en comercio y esa delación de los americanos parece haber sido intentada con el fin de favorecer sus especulaciones» (28).

Diplomacia y especulación mercantil parecen estar presente en todas las actuaciones de Sarmiento. La más borrascosa de estas empresas fue la de fletar en 1810 una goleta, "La Ramona", con un cargamento de cañones, armas y municiones de guerra

(26) AHN. Estado, Leg. 5.551.

(27) AHN. Estado, Leg. 5.551.

(28) AHN. Estado. Leg. 5.553. 
con destino a Maracaibo para abastecer a las tropas que en esa ciudad apoyaban la causa realista. Pero desde un principio su envío fue obstaculizado. En Norteamérica, donde la simpatía a la causa independentista era notable se le puso todo tipo de impedimentos judiciales para fletarlo, acusándole de emplear los cañones para armarse como buque de guerra en alta mar, por lo que iba en contra de la neutralidad de los EE.UU. Onís señala al respecto que Sarmiento "por un acto de patriotismo ofrecía a $\mathrm{Su}$ Majestad el coste de la factura, además de pagar el flete de la goleta, que no dejaba de ser de consideración». Sostiene que la culpa del embargo se debió a «los jurados, elegidos entre la ínfima clase del pueblo y de los más acérrimos demócratas, que aquí es sinónimo de francés, y al juez, que es de los más acérrimos demócratas». El embajador español expresaba su descontento con esa tradicional fórmula de los jurados, fiel expresión del estado de opinión en Norteamérica, en los siguientes términos: "La constitución americana y su tribunal de jurados, que llaman el paladín de la libertad, cuando está patente que elegidos entre la ínfima clase del pueblo que son los demócratas, prostituyen la justicia y su conciencia en sostener al partido del Gobiernon (29).

"La Ramona» zarpó de Filadelfia el 6 de octubre de 1810. Como medida de precaución, ante la posibilidad de que Maracaibo estuviese ocupada por los insurgentes hizo escala en Curaçao, que por aquel entonces estaba bajo soberanía británica. Aunque Gran Bretaña se había declarado neutral en el conflicto entre España y sus colonias, sus funcionarios en esa isla caribeña se inclinaban por la causa venezolana.

El Gobierno de Curaçao ordenó el secuestro de la goleta. En su informe hacía constar algo que no debe extrañarnos dentro de las actividades comerciales de Sarmiento; la goleta era americana y su mismo patrón, Sarmiento, era súbdito de los Estados Unidos. Los informes nos of recen los siguientes datos sobre el ordenamiento de «La Romana»:

"La totalidad del cargamento que está a bordo, aún los pertrechos de guerras, es propiedad privada, y ha sido embargado con fines especulativos. El resto del cargamento se compone de artículos franceses y de las Indias Orientales y monta de acuerdo con las facturas, alrededor de 7.000 dólares, el navío está estimado en aproximadamente 10.000 dólares más».

(29) AHN. Estadu. Leg. 5.553. 
El Gobernador Layard hacía constar la paradoja de un navío de esta naturaleza sin llevar un cañón y con una tripulación norteamericana que no podía defenderlo si encontrase un enemigo dada la neutralidad de Estados Unidos. E incluso si fuera un navío nacional, también parece lo más extraordinario el que fuera empleado en un viaje nacional. Las apreciaciones del británico son contundentes sobre las contradicciones de este buque:

«Ningún navío mercante español europeo podía consistentemente tomar un cargamento de pertrechos de guerra, artículos franceses y de las Indias Orientales en un puerto de los Estados Unidos, consiguientemente "La Ramona" (admitiendo que fuera un navío de guerra) no podía gozar como navío mercante tales privilegios, y si fuera un navío del Rey ¿para qué la necesidad de ser despachado en una aduana en los Estados Unidos?» (30).

El embargo dejaba a las claras que el armamento almacenado en "La Ramona» era en su mayoría de pertrechos de guerra. Sin embargo, en sus reclamaciones, Onís, siguiendo la técnica de Sarmiento de elevar a cifras desproporcionadas sus pérdidas, cifró en 10.000 fusiles su cargamento.

La goleta estuvo detenida en Curaçao según Sarmiento hasta marzo de 1814 , con lo que la detención fue beneficiosa para los insurgentes. El comerciante afirma que tuvo que efectuar su venta en Curaçao por menos de la mitad de su valor (31). Sin embargo, "La Ramona" se entregó a los españoles y llegó a Coro entre septiembre y octubre de 1811, por lo que no son ciertas esas interesadas declaraciones de Sarmiento, que argüía además que el producto del cargamento de la goleta fue a parar al gobierno de Maracaibo a consecuencia de las urgencias de la guerra. Roscio en su carta a Andrés Bello, representante venezolano en Londres, dejaba bien claro el doble propósito de Sarmiento y Onís: «Los contrarios pidieron armamento a Onís... A fuerza de las intrigas de Onís y de su arlequín Sarmiento hubo de salir (de Filadelfia) al mes siguiente con destino a introducir en Coro y Maracaibo parte de su cargamento, y llevar todo le demás a Veracruz» (32).

(30) Documentos de las cancillerias europeas sobre la independencia venezolana. Estudio preliminar de Carracciolo Parra Pérez. Caracas, 1962. Tomo I, págs. 213-215.

(31) AHN. Estado. Leg. 5.551.

(32) Carlos Pi Sunyer, C. "La Goleta Ramona". Boletín de la Academia Nacional de la Historia, nº 153. Caracas, 1956, pág. 73. 
Las graves pérdidas económicas acaecidas en sus empresas comerciales a consecuencia del triunfo de la causa de los insurgentes y de la incapacidad de la hacienda pública estatal para hacer frente a las deudas contraídas por Sarmiento, se tradujeron en una casi permanente situación de quiebra económica para el portugués. Pero en tan críticos trances mostró a las claras su peculiar personalidad y su singular concepción de la vida y del mundo que le rodeaba. Su cuñada Peggy Craig, esposa de John Craig, diría de él que tan pronto como se rehabilitaba de los pleitos por suspensión de pagos gracias a la fianza de Onís «otra vez volvía a ocupar su lugar entre los comerciantes y creía tan usual tener su cocina francesa, su mayordomo, etc. Tras pasar una temporada en prisión en 1811 dio una severa paliza en un café al pastelero que le había arrojado a la prisión». Ella relataba que deseaba que "abandonase Filadelfia para no ofenderse oyendo hablar de él» y especificaba las trágicas circunstancias de su familia. A su hijo Diego Sarmiento ues ahora en mi opinión un desgraciado que no puede obtener empleo y no conocer qué hacer para sobrevivir». En 1812 Diego que se había casado no felizmente y había tenido tres hijos, había roto su matrimonio. «Su padre es un infeliz libertino, no tenía un dólar que darle, hipotecadas todas sus propiedades, pasaba dos semanas en la cárcel viviendo sobre tórtolas y a vueltas con sus negociaciones» (33).

Pero la familia Craig recogió a Diego, pasándole una pensión. Tuvo una muerte desgraciada en 1822, al igual que dos de sus hijos varones, Fernando y Luis, el primero de los cuales murió a los 24 años, y el segundo desapareció, suponiéndose que fue asesinado. La única hija, Jane Josephine, fue recogida por sus tías, quien siguiendo una cuidada política matrimonial asumida por la burguesía de su tiempo se casó primero con su primo John C. Craig, hijo del ya referido John Craig, y en segundas nupcias con Edward Biddle, hijo de Nicholas Biddle. De ella se diría que "era la única respetable Sarmiento» (34).

La ruptura de Sarmiento con su mujer ya desde esas fechas era evidente. En enero de 1813 renunció a cobrar los réditos de la herencia de su esposa, aludiendo que «no tenía órdenes para ello de su esposa, habiendo particulares razones para no participar

(33) Vid. [2], pág. 22.

(34) Ibidem, págs. 22-23. 
en ningún asunto pecuniario con la familia Craig» (35). En Venezuela los insurgentes le confiscaron todas sus propiedades, entre ellas una casa y sitio que poseía en el pueblo de Maiquetía antes del terremoto de 1812 (36).

Atravesaba por unas circunstancias muy críticas, en un momento en que tan sólo gozaba de la confianza de las autoridades españolas. Su papel como espía de la Embajada Española es una faceta muy interesante de su atrabiliaria personalidad. Onís en una carta particular a su sobrino fechada el 14 de marzo de 1812, hacía un retrato bastante fidedigno del Sarmiento que él conocía:

«Por lo que toca a Sarmiento, de quien me has hablado en otras cartas como un tunante, no lo extraño, pues como es el único español en este país que tiene patriotismo acendrado y puro, y como en virtud de él se ha sacrificado en términos de haber perdido cuanto tenía, tiene muchos enemigos. Mas el Marqués de Casa Irujo es buen testigo de su conducta y va con él a España para confundir a cuantos pícaros de que abunda el mundo y más que ningún paraje en donde yo me halló. Su carácter es algo inconsecuente en cosas de poca monta: es gastador, y como ha sido rico, se ha hecho, como te he dicho, muchos enemigos" (37).

De sus actividades como ya hemos hablado en otro lugar (38), por lo que aquí nos ocuparemos de sus informes sobre la Primera República Venezolana.

En junio de 1810 arriban a Baltimore los representantes de la Primera República de Venezuela para solicitar apoyo al Gobierno norteamericano. Onís decide enviar a Sarmiento para sondearlos. Las razones que le llevan a tal designación obedecían a "su acreditado celo y patriotismo y porque ha residido doce años en Caracas, tiene bienes en aquella provincia y conexiones con toda la nobleza de aquél país».

Los informes de Sarmiento tienen particular interés. Del más

(35) The Historical Society of Pennsylvania. Biddle and Craig Family Papers. Box 180 Folder 15.

(36) AHN. Estado. Leg. 5.551.

(37) Angel DEL Río, La misión de Don Luis de Onis en los Estados Unidos (1809-1819). Nueva York, 1981, págs. 224-225.

(38) Manuel HeRnÁNDEZ González, "Entre el apoyo a la emancipación americana y el servicio al colonialismo español: las contradictorias actividades del liberal maderiense Cabral de Noroña en los Estados Unidos (1811-1819). II Congreso Internacional de Historia de Madeira. Funchal, 1989, págs. 365-378. 
importante de los enviados, Telesforo Orea, natural del Puerto de la Cruz (Tenerife) y viejo conocido suyo desde sus años de las islas Canarias diría que es "hermano de Gonzalo de Orea de Cádiz, un grande intrigante y garante de todas las revoluciones, que habla muy bien el inglés y es capaz de desempeñar cualquier comisión de importancia, que es muy conocido suyo y es el principal diputado o ministro de aquel nuevo gobiernom. De Juan Vicente Bolívar, hermano del libertador, diría que "es un criollo de Caracas, de una familia distinguida y ha sido educado en Francia». Su objetivo en Norteamérica era hacer proposiciones de amistad y comercio. La interpretación que extrajo Sarmiento de ellos no deja de tener interés. Le dicen que han depuesto a todas las autoridades, que el cabildo procede en unión de la Junta, y que han jurado la independencia interin vuelve Fernando VII al trono, que no reconocerán otro gobierno que el de su legítimo monarca, y que se han otorgado una Constitución, y que Orea le ha insinuado que no necesitan de la americana. El comerciante isleño le refirió «Desengáñese V.M. amigo, la Península a la hora de ésta está sometida a Bonaparte y la España jamás puede resistir su contienda con la Francia por falta de medios y recursos para seguir la guerra, pues necesitará a lo menos de 200 millones de duros anuales, y éstos no puede suplirlos las colonias». A lo que Sarmiento le contestó, "Amigo Orea, mucho siento que V.M. se haya embarcado en una causa tan fea y desgraciada, pues me temo que tanto V.M. como su familia, y quizás todos los blancos han de ser víctima de ella, pues es de temer que la excesiva cantidad de negros de que abunda la Provincia quieran recobrar su libertad y se alcen con la propiedad de VMS, asesinando sus mujeres e hijos, como ha sucedido en Santo Domingon. A esa reconvención respondió Orea que ello le podría pasar a Sarmiento si se hallase en Venezuela, por haber tenido comisiones de la Hacienda y que el producto de las harinas ya se había sacado de las arcas para darle mejor destino que el entregárselo a él o enviarlo a España como lo había solicitado" (39).

Sarmiento se enteró de las gestiones de un sobrino de Orea, Casiano de Medranda, que él por error llama Cayetano, el cual había sido enviado por la Junta ante el almirantazgo inglés en las Bermudas con iguales proposiciones que las que se llevaban a los Estados Unidos. Otro isleño que marchó con ellos en la expedición, Juan de Iriarte, le dijo que era un buen patriota y que venía escapado para "no someterse a los disparates que los

(39) AHN. Estado. Leg. 5.636. 
demás hacían. Que en Caracas no había harinas para mantenerse ni municiones para resistir a cualquier fuerza que se enviase contra aquella provincia y que estaba pronto a poner su cabeza, a que cinco o seis mil hombres mandados inmediatamente eran suficientes para sujetar los insurgentes». Las instrucciones de Sarmiento eran precisas:

"Una de las cosas más importantes en el momento actual es impedir que a los caraqueños se les envíen víveres y sobre todo municiones, y que se les haga ver la incongruencia de su procedern.

Además debe enviarse copia de estos informes al ministro inglés Jackson para que

«procure inducir a los cruceros ingleses a que bloquean los puertos de Caracas e impidan que les lleguen armas y municiones» (40).

Las perspectivas de análisis de los informes de Sarmiento nos ilustran las ideas y las propuestas de los insurgentes caraqueños, de sus intenciones y reales posibilidades, de los inevitables conflictos sociales que se originarán, y de la urgencia de una ayuda internacional que demandaba la recién creada república; pero también de las limitaciones de una España invadida por los franceses y que se pensaba iba a seguir bajo su dominio y a la que ellos no iban a pagar el esfuerzo económico de su reconstrucción. Y ante todo de la ingenuidad de las autoridades espanolas de aquel momento de creer en el apoyo de una Inglaterra que tácticamente había hecho causa común con España en su guerra contra Napoleón, pero que codiciaba las ventajas que a ella se le abrirían con la independencia de las nuevas repúblicas.

Durante los últimos años Sarmiento ya arruinado no se resistió a la paradoja de continuar como funcionario del Gobierno Español, como Comisionado por Su Majestad para la liquidación y cobranza de las cantidades adeudadas al Erario por resultas de las expediciones neutrales hechas a América, y como esperpéntico y nunca efectivo Director de Tabacos de la Provincia de Venezuela, y el hecho de ser el máximo deudor de la Real Hacienda. Un informe calificado de reservadísimo fechado el 24 de diciembre de 1815 expresaría que "tratándose de averiguar si es cierto

(40) Ibidem. 
que el Coronel Sarmiento se ha aprovechado de algunos millones correspondientes a la Real Hacienda es la voluntad del Rey que hasta que dicha averiguación se verifique se le detenga de un modo que no le pueda resultar sospechoso» (41).

El gobierno español era consciente de los fraudes de Sarmiento y de la inexistencia de contabilidad alguna en buen número de sus empresas con la Real Hacienda, pero también conocía la ruina total por la que éste atravesaba. En 1818 marchó a Madrid para una comisión sobre el Tratado de las Floridas que gestionaba Onís con los Estados Unidos. El Weeklky Aurora de Filadelfia de 18 de enero de 1819 se hacía eco de la confusión y el embarazo en la Corte española de un negocio escandaloso de Sarmiento en relación con la cesión de las Floridas a los Estados Unidos. Pensamos que se refería a su propuesta hecha en Madrid a 20 de enero de 1818 de que "se le concedan por sus méritos para sí y sus descendientes un terreno baldío en Las Floridas en los sitios que se le señalen de 400.000 fanegadas a lo menos». En tan esperpéntica propuesta que escondía una escandalosa venta posterior a los norteamericanos por la cesión de esos terrenos, se agregaba como «nuevo mérito» el siguiente:

«hallándose apurado el ministro en Filadelfia por no poder llevar el pedido de 6.000 fusiles, 2.000 sables y 1.000 pares de pistolas que con mayor urgencia se hacía el Virrey de Lima, comisionó al exponente quien tomando sobre sí una responsabilidad de 100.000 duros sin detenerse ni un momento, ha tenido la satisfacción de dar esta buena prueba de amor a la Patria» (42).

Y con tan significativa petición, que muestra a las claras el espíritu de una época, finalizó su existencia Sarmiento en torno a 1819. Su familia creía que murió asesinado y pensamos que eso debió pasar en las intrigas palaciegas en las pugnas de las camarillas de aquellos años. Su biógrafo, Alvarez Rixo, nos relata que reapareció este personaje en la Corte, "donde siempre apasionado por el fausto y lucimiento se le veía pasar y servirse del magnífico coche que había sido del uso del Príncipe de la Paz su antiguo favorecedor». Fue invitado a la casa del Marqués de CasaIrujo, por aquel entonces ministro de Estado de Fernando VII, y «al levantarse de la mesa le atajaron terribles vómitos, tan pertinaces que le causaron su muerte». Se afirmó que era aficionado

(41) AHN. Estado. Leg. 5.551.

(42) Idem. 
en extremo a los escabeches y «se había excedido aquel día en comer algo de ellos, que estaban colocados en tarritos de cobre» (43). Nada de extrañar tiene que de acuerdo con la visión de su familia hay sido envenenado.

Diez años después, en 1829, su viuda Catalina Craig reclamó al Estado Español un alcance a su favor en las cuentas de su cónyuge con la Hacienda por un valor de 69.178 pesos, a lo que el Gobierno contestó que había un claro fraude en tales cuentas «a pesar de todos los servicios preconizados por Sarmiento como empleado de Su Majestad» y hace constar años después, el 27 de agosto de 1832, que no recurrirá judicialmente contra su viuda porque ésta reside desde otoño último en Lexington, capital de Kentucky bajo el amparo de su yerno Eduardo Barry, quien le sostiene a pesar de sus escasos medios que le obligaron a dejar Filadelfia y traslarse allí con el fin de establecer una casa de educación" (44).

(43) HeRnández y dE PAz [1], pág. 475.

(44) AHN. Estado. Leg. 5.551. 